\title{
Hugh Owen Thomas: the cripple's champion
}

\author{
A J Carter
}

Nearly 60 years after he died, surgeons from around the world still honour the memory of Sir Robert Jones, the father of modern British orthopaedics. Sir Robert lived and worked at a time when crippled children were a common sight on Britain's streets, and one of his greatest achievements was to show that many of these children - the victims chiefly of tuberculosis, rickets, and poliomyelitis - could be cured. The principles of treatment which he introduced, however, were not new. They had been established half a century before by his uncle and teacher, Hugh Owen Thomas, who died 100 years ago.

Sadly, and largely for reasons of his own making, Thomas's principles were not widely accepted by the medical profession during his lifetime. Many people suffered needlessly as a result, and John Ridlon, an American surgeon who knew both Thomas and his nephew, said that "one of the greatest things Robert Jones ever did was to make the main principles of Hugh Owen Thomas acceptable to the medical profession."

Of the three crippling diseases, by far the most common was tuberculosis which, in children, was largely a disease of joints, particularly the hip joint and spine. Many of its victims were chronic invalids, "hopeless cripples" in the language of the day, often reduced to begging and an embarrassment to a society that prided itself on its achievements. So many were affected that in 1893 a surgeon at Edinburgh's Royal Hospital for Sick Children wrote: "Had I four times the number of beds at my disposal, I could fill them all in a week with cases of spinal diseases and hip-joint disease in its late manifestation... only the worst can be admitted."'

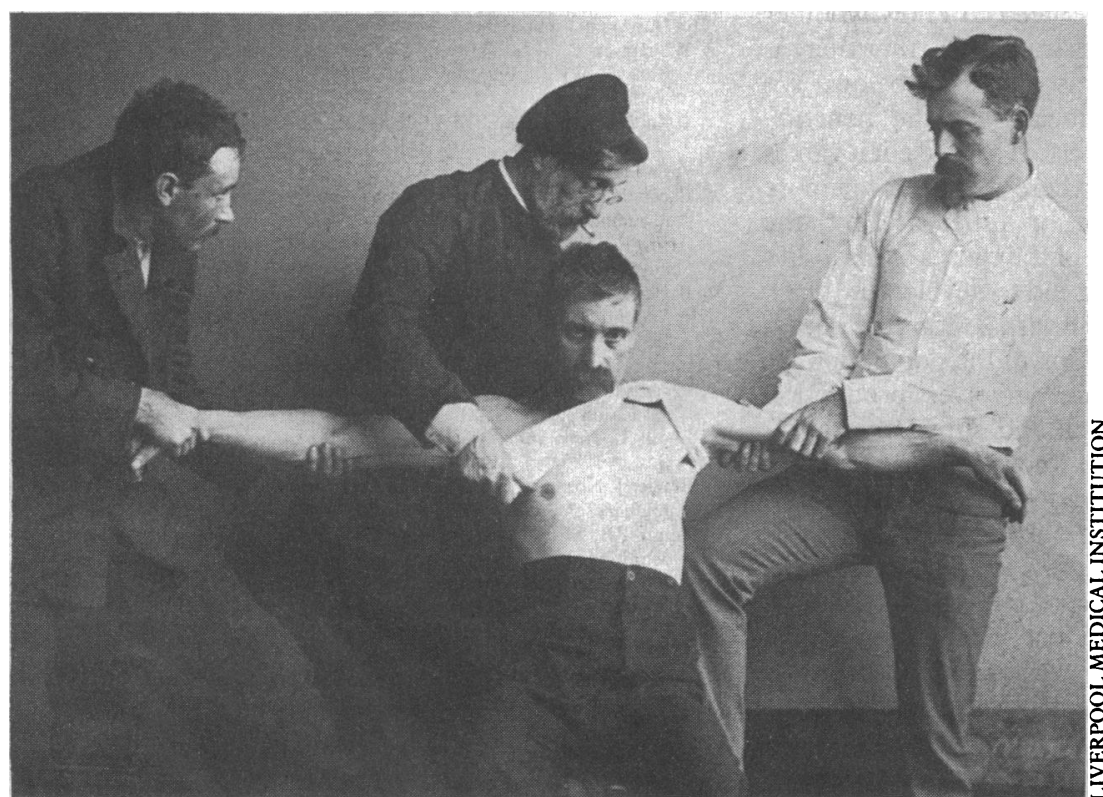

FIG 1-Hugh Owen Thomas and Robert fones (right) with assistant. An early example of clinical photography

\section{Early days}

Hugh Owen Thomas was born at a time when bone and joint disorders were still largely the domain of totally unqualified practitioners known as bone setters, who often used skills that had been handed down over many generations. Thomas himself came from one such line. His family history is shrouded in mystery and romance but goes back to a stormy night sometime around 1740, when an ancestor of unknown origin was washed ashore from a shipwreck off the Anglesey coast. That ancestor, Hugh Owen Thomas's great grandfather, was adopted locally, given a Welsh name, and went on to found a dynasty of traditional bone setters credited with almost supernatural powers of healing.

Two generations later Hugh's father, Evan Thomas, decided to take the family business from Anglesey to the then rapidly developing port of Liverpool. Hugh himself was born in 1834 at Tyn Llan, Bodedern, Anglesey, where his mother was enjoying a family holiday.

Largely because of increasing hostility from within the profession to the activities of non-qualified practitioners, Evan Thomas decided that his five sons should be the first of the line to enjoy the benefits of a medical training. Hugh, the eldest, began his medical studies a Edinburgh University in 1854 , gained his $\mathrm{MB}, \mathrm{BS}$ in 1858 and, after a spell in London and Paris, returned to join his father's practice in Liverpool in 1860 .

Unfortunately - and perhaps inevitably-the partnership between a now highly trained medical man and an unqualified bone setter was not a success. Hugh Owen Thomas left his father's practice in 1866 to set up on his own at 11 Nelson Street, an address destined to go down in history as the birthplace of modern British orthopaedics. The arrival there in 1873 of his young nephew Robert Jones, about to embark on a medical training at Liverpool University, was the beginning of a partnership which was to prove legendary.

Thomas's patients at the Nelson Street practice came mostly from the nearby docks, and many were sailors who had returned from the far corners of the globe with fractures and dislocations that had remained untreated for the weeks or months they had remained at sea. Thomas treated these most difficult of injuries by using the traditional skills of his ancestorsrecruiting, where necessary, the additional assistance of up to half a dozen labourers brought in specially from the street (fig 1). When, however, the treatment of diseased as well as dislocated joints began to attract his attention it was to his more conventional medical training that Thomas turned for guidance.

\section{Nature's remedy}

During his student days in Edinburgh, Thomas had studied the writings of the seventeenth century physician Thomas Sydenham, who taught that illnesses were best treated by working with nature rather than against her. ${ }^{4}$ From Brodie and Hilton in London 


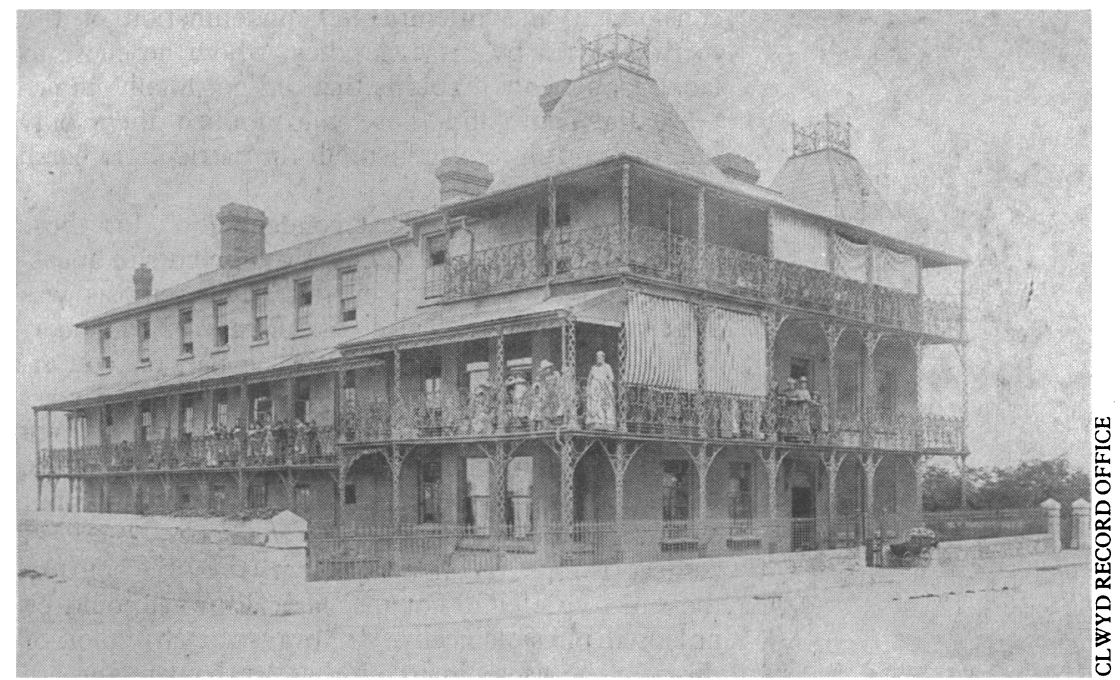

FIG 2-Sea Side Hospital and Convalescent Home, Rhyl the open air on specially constructed balconies. It was the first children's hospital to advocate fresh air as an integral part of treatment and provided Thomas with an excellent opportunity to try out his ideas. ${ }^{9}$ The hospital's committee, which included W E Gladstone, MP-Liverpool's greatest son-must have been impressed with what they saw of Thomas's methods, $\frac{}{2}$ for they gave him what proved to be virtually the only official recognition that he received during his lifetime:

"The committee would also express their best thanks to Drc Thomas of Liverpool for the kind and liberal way in which he $\overline{\overline{\bar{N}}}$. has, at considerable inconvenience to himself, frequently visited the hospital in order to illustrate the working of surgical appliances invented by himself, which appliances? have proved the greatest possible benefit to the patients."10

\section{Later developments}

This hospital at Rhyl, now the Royal Alexandra Hospital, has its place in orthopaedic history. It was. here, towards the end of Thomas's life, that theo remarkable crippled nurse, Agnes Hunt, began her training. ${ }^{9}$ This formidable lady had herself been afflicted since childhood with a tuberculous hip, and $N$ the inspiration she found at Rhyl led her to set up acr small convalescent home in the Shropshire village ofoo Baschurch, where she began to nurse crippled children? outside, all the year round, in a collection of primitiven farm sheds." Agnes Hunt later persuaded Robert $\overrightarrow{-}$ Jones, whom she had met originally as a patient, to visito Baschurch. So impressed was he with what he saw there that in 1907 he decided to visit and operate on $a$ वृ
regular monthly basis.

Baschurch, the first fully open air orthopaedic $\overrightarrow{0}$ hospital in the world, became the model not only fore the present Robert Jones and Agnes Hunt Orthopaedic Hospital at Oswestry but also for the national schemeo for cripples which, during the 1920s under Sir Robert Jones's leadership, set up a network of open airo country hospital schools in such places as Stanmore Wrightington, Harlow Wood, and Biddulph Grange. 10

A visitor to any of these hospitals between the warso $\overrightarrow{\vec{B}}$ would have found rows of children lying in the sun on Thomas frames (fig 3), and yet, with only a few exceptions, Thomas's pioneering work was destined to. remain unknown during his lifetime. Where it wass known it was overwhelmingly rejected.

Although isolated from his colleagues, Thomas waso fortunate in having one loyal friend and supporter Rushton Parker, a young Liverpool surgeon later tô become professor of surgery in that town. One day during the early 1870s Rushton Parker had comeo across a boy in the street who, in spite of having one hip immobilised in a splint, was managing to walk on crutches. The boy achieved this thanks to a patten, oro

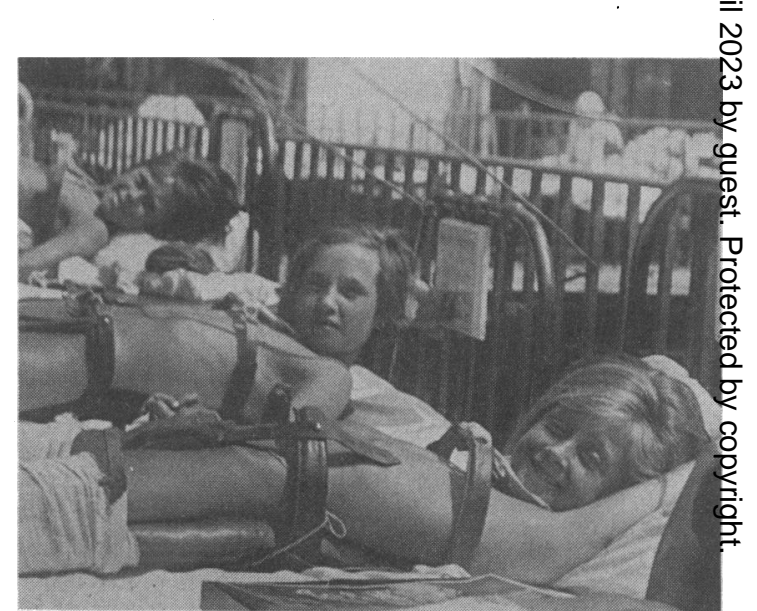

FIG 3-Suntanned children on Thomas frames, Woodlands Hospital, Birmingham, 1927 


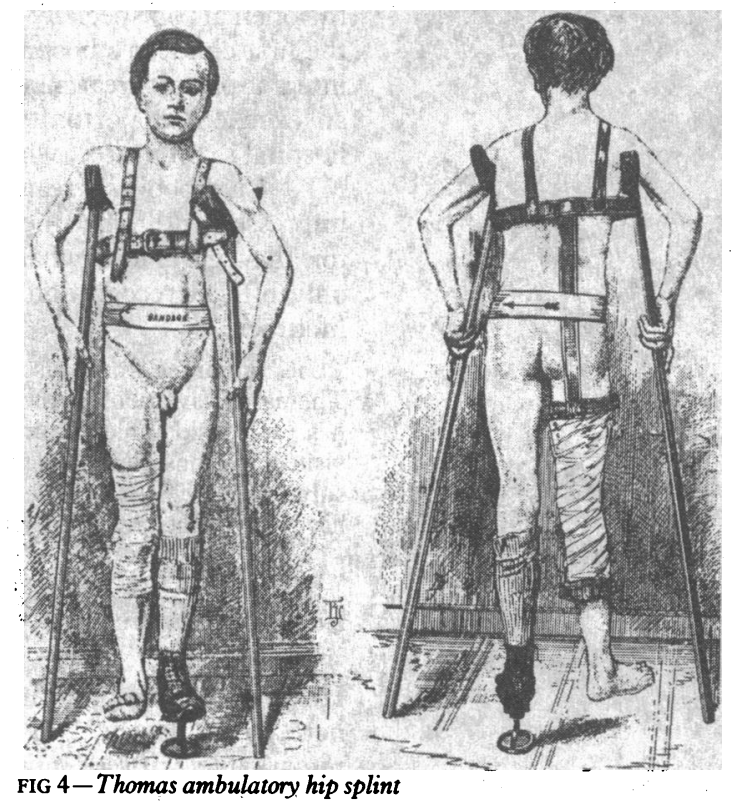

thick sole, which raised his good leg four inches off the ground (fig 4). So impressed was Rushton Parker with this ingenious idea that he quickly sought out Thomas, urged him to publish his work, and himself went down to London to demonstrate his methods at University College Hospital. ${ }^{4}$

Thomas's methods quickly gained acceptance at a number of London hospitals and particularly at the Alexandra Hospital for Children with Hip Disease in Queen Square, which had opened in 1867 to provide long term nursing care for children from the nearby Great Ormond Street establishment. ${ }^{1314}$ The surgeons at this early specialist hospital adopted Thomas's methods with enthusiasm, and children on Thomas ambulatory hip splints were to be seen walking around Queen Square as early as 1876 , within a year of Thomas first writing about them. ${ }^{4}$ is

\section{Standing alone}

Elsewhere almost half a century was to pass before Thomas's principles finally gained general acceptance, and this deep rooted and longlasting rejection of Thomas's ideas by the medical profession can be understood only within the context of the man himself -his personality, his strange appearance, and, perhaps not least, his unorthodox ancestry.

Thomas's appearance is in fact easily explained - his huge gauntlet gloves and buttoned up greatcoat served to protect him from Liverpool's chilling sea breezes; his "second mate's discharge cap" concealed the scar of an old eye injury; and the ever present lighted cigarette between his lips was a protective habit he had acquired while visiting patients in their homes during a cholera epidemic (fig 5).

His personality was much more difficult to explain. Professionally speaking, he was a loner. He neither applied for a surgical fellowship (except in extreme youth when he was ineligible) nor did he attend the meetings to which he was frequently invited. During the late 1870 s, however, he decided that, with no children of his own and with no position on the staff of a major hospital, his ideas might well not outlive him. He therefore began to write, and this was when his problems with his colleagues began.

At first Thomas's publications were printed only locally, but there is little doubt that they soon found a wider audience. Possibly because he wrote late at night and after a hard day's work, his "contributions" consisted for the most part of a long winded, ill considered, and intemperate condemnation of the methods used by his colleagues, whom he chose to label "opponents." Splints that did not totally immobilise the joint (and those who applied them only intermittently) were singled out for particularly harsh criticism.

He reserved his greatest condemnation for those who took advantage of recent developments in anaes-. thesia and antisepsis to operate. Tuberculosis was $\overrightarrow{\vec{A}}$ largely, but not exclusively, a disease of the poor. While often willing to treat better off patients conservatively, many surgeons preferred in working class $\overline{\bar{c}}$ children to resort to early excision of the joint or even to $\vec{\nabla}$ amputation (with the results that can be seen in figure 6). Thomas regarded such mutilating operations as not is only unnatural but unnecessary and spoke bitterly of $\vec{\circ}$ "enterprising surgeons who, inspired by the spirit of the times, prefer to cut mechanically what could be $\vec{\omega}$ unloosed physiologically." 16 Always the champion of the poor, he also pointed out that "such operations are $\exists$ performed almost entirely on the inmates of our $\omega$ charities and rarely upon relatives of the subscribers to $\omega$ those institutions."

Although Thomas's non-interventionist philosophy was far from popular, what really upset his colleagues $\vec{v}$ was the fact that he, a totally unknown provincial, had chosen to criticise some of the most distinguished figures in the land. Almost to a man, the profession decided that Thomas was not a gentleman. Ridlon, $\longrightarrow$ after visiting hospitals in many other cities, reported

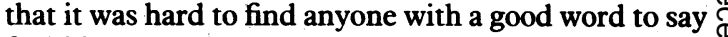
for him. ${ }^{3}$ Even those who might otherwise have 3 supported Thomas now chose to reject him. While this $\mathbb{D}$ in itself might not have mattered, the fact that they chose to reject his principles as well was to have $\&$ profound consequences for years to come.

\section{The people's friend}

Hugh Owen Thomas died of pneumonia in 1891 at the age of 57, and thousands of Liverpool's poor, $\stackrel{\unrhd}{\unrhd}$ unconcerned by his professional difficulties, flocked to $\overrightarrow{\vec{B}}$ his funeral. Rather more surprisingly, perhaps, many $\frac{3}{3}$ of his own colleagues, often his most implacable

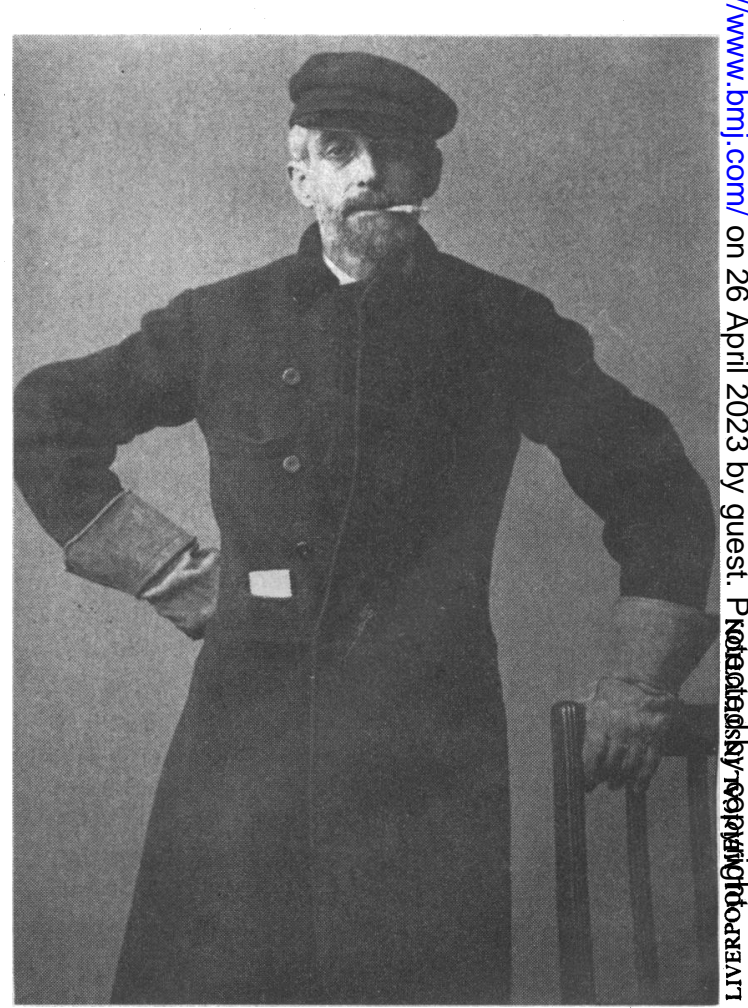

FIG 5-Hugh Owen Thomas 


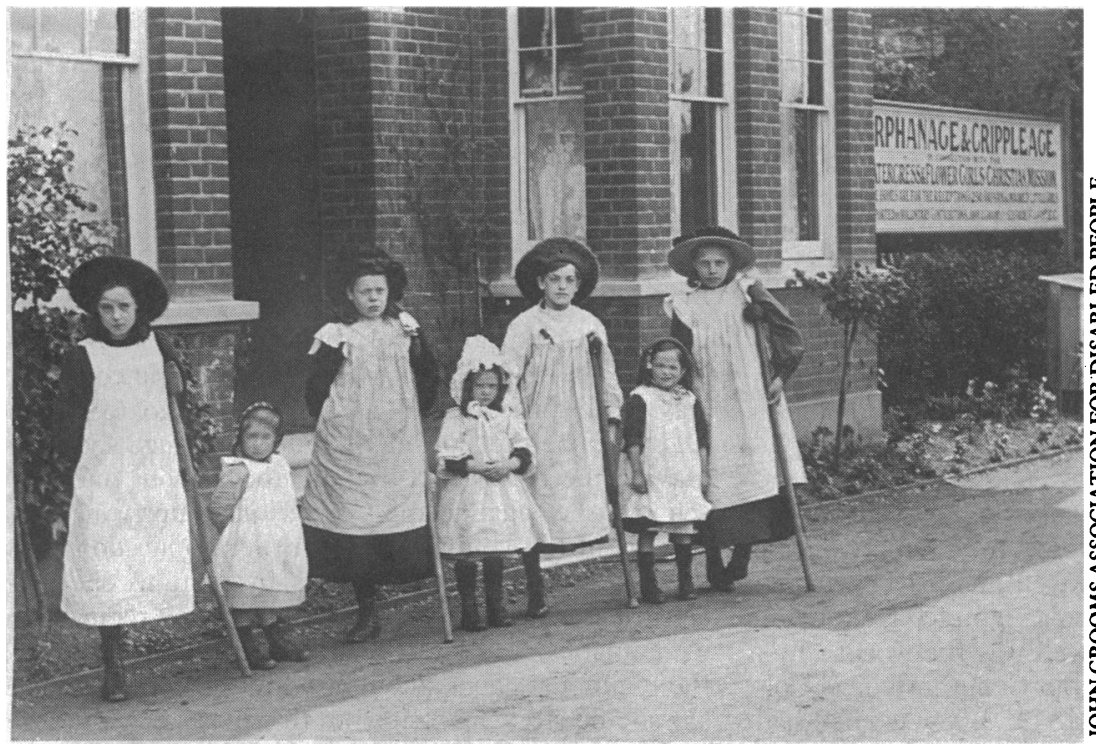

FIG 6-Child amputees outside a "crippleage," 1910

opponents, also attended. The occasion was reported by the Lancet in unusually emotional terms:

A grief so profound and widespread as that which was manifested at Liverpool on the tenth instant when the remains of Dr Hugh Owen Thomas were laid to rest, is seldom witnessed. There can be no more eloquent or touching testimony to the worth of a man's character than the tears of the poor among whom he lived. The toilers at our docks and warehouses are not sensitive beings, and the daily struggle of their lives is too earnest to admit of much display of sentiment. To see thousands of these, then, men as well as women, as any one might have done in Liverpool last Saturday, stirred to their very depths by an emotion that found expression in passionate sobs and tears, as they lined the streets or pressed forward to gaze into the open grave, proves that its silent occupant had won his way to their hearts. ${ }^{17}$

Although it has been suggested that Thomas's principles might well have died with him had it not been for Sir Robert Jones, ${ }^{18}$ this is plainly not so. His methods had gained acceptance in a small number of hospitals during his lifetime. For many years after his death, however, and well into this century, crippled children who could have been cured continued to languish in homes for the chronically sick and incurable. Although there were other reasons for this sad state of affairs - there still existed an age old antipathy to the cripple in many quarters - at least part of the blame must lie with a professional unease about Thomas that lingered for many years. It was only when the number of crippled children became swollen by an even greater number of injured ex-servicemen from the first world war that Thomas's principles were finally accepted.

\section{Recognition}

The Thomas splint reduced the mortality from fractures of the femur by $75 \%$ during the first world war, saving many thousands of lives, ${ }^{1}$ and this brought Thomas the professional recognition that had eluded him during his lifetime. In 1918 the Hunterian professor of surgery, Sir Arthur Keith, gave a lecture on Thomas and his principles to the Royal College of Surgeons; later, in an editorial, the British Medical fournal was generous in its praise:
Of no man can it be more truly said that time has justified his teaching and practice. The experience of the war has proved that the principles he laid down for the treatment of injuries and deformities of the limbs were sound and the appliances he devised the best. Thomas's realization that repair could be "fostered only by the patient, personal application of the surgeon's head and hand, day after day, week after week, month after month, year after year" was of even greater value than his discovery of the fuller meaning of the word "rest" and his genius in designing new means of giving rest. No one who will take the trouble to ascertain what he did, and the circumstances under which he accomplished his life's work, will fail to see that he has earned himself a place among great British surgeons. No greater compliment could have been paid to his memory, ideas, and principles of treatment than the selection of his nephew, Sir Robert Jones, for the important position of Director of Orthopaedic Surgery to the British Army during the War.. Thus has Thomas vicariously contributed to save many a wounded soldier from crippledom, and done an immense service to the nation."

Robert Jones took over the Nelson Street rooms after Thomas's death and, with the gentle powers of diplomacy for which he was renowned, brought his master's work to the attention of a grateful world. Of his nephew and pupil, Thomas once said: "Jones is a dear fellow and knows his work, but he lacks the fighting spirit."' Thomas had failed to realise that original ideas are of limited value unless accompanied by the ability to communicate them successfully to others; in this regard, Sir Robert Jones's quiet reasoning pen was to prove far mightier than Thomas's fighting one ever did. For once in his life, Hugh Owen Thomas was wrong.

Of the many orthopaedic surgeons, present and retired, who have provided invaluable assistance, I would like to thank in particular Professor Robert Owen, Mr Denys Wainwright, and Mr John Cholmeley. Dr Roger Cooter of the Wellcome Medical History Unit, University of Manchester, provided much reference material; $\mathrm{Mr}$ Geoffrey Yeo and $\mathrm{Mr}$ Paul Mason, archivists respectively at St Bartholomew's Hospital and Clwyd Record Office, supplied historical information on the two "Alexandra" hospitals. I would also like to express my appreciation to Miss Marie Carter, $\mathrm{Mr}$ Peter Smith, and Mrs Janice Mayhew of the Orthopaedic Librarians Association, and to Mr Derek Crook and Mrs Irene Fenton, librarians respectively of the Liverpool Medical Institution and the North Staffordshire Medical Institute.

1 Watson F. The life of Sir Robert fones. London: Hodder and Stoughton, 1934 2 Bell J. Five years' surgery. Edinburgh Hospital Reports 1893;1:467.

3 Watson F. Hugh Owen Thomas, a personal study. Oxford: Oxford University Press, 1934.

4 Le Vay. D. The life of Hugh Owen Thomas. Edinburgh: E and S Livingstone, 1956.

5 McCrae Aitken D. Hugh Owen Thomas, his principles and practice. Oxford: Oxford University Press, 1935:61.

6 Hughes Bennett J. Clinical reports. Monthly foumal of Medical Science $1851: 2: 163-5$.

7 Shepherd D. A history of the Liverpool Medical Institution. Liverpool: The Institution, 1979:161.

8 Thomas HO. Diseases of hip, knee and ankle joints. London: H K Lewis, 1878:169n.

9 Hunt A. Reminiscences. Oswestry: Robert Jones and Agnes Hunt Orthopaedic Hospital, 1935:65.

10 Royal Alexandra Hospital. Annual reports, 1872-85. Clwyd Record Office. (Ref $\mathrm{H} / 2 / 1$.)

11 Watson-Jones R. Dame Agnes Hunt. F Bone foint Surg [Br] 1948;30:710.

12 Osmond-Clarke $\mathrm{H}$. Half a century of orthopaedic progress in Great Britain $f$ Bone foint Surg [Br] 1950;32:627-31.

13 Smith S. The Alexandra Hospital for Children with Hip Disease. The Child 1912-13;3:728-31.

14 Kosky J. Mutual friends: Charles Dickens and Great Ormond Street Children's Hospital. London: Weidenfeld and Nicolson, 1989:57.

15 Alexandra Hospital. Clinical records, 1870-1910. Archive Department, St Bartholomew's Hospital. (Ref AMR 6.)

16 Thomas HO. The principle of treatment of fractures and dislocations. Contributions to Surgery and Medicine 1886;6:93-4.

17 Hugh Owen Thomas, MD, MRCS [obituary]. Lancet 1891;i: 174-5.

18 Robert Jones and Agnes Hunt Orthopaedic Hospital. Heritage of Oswestry. Oswestry: The Hospital, 1961:34

19 Memorial to H O Thomas. BMf 1919;i:110. 